Electronic Supplementary Information (ESI)

\title{
Sponge-like Porous Manganese(II,III) Oxide as a Highly Efficient Cathode Material for Rechargeable Magnesium Ion Batteries
}

Lu Wang ${ }^{1}$, Karina Asheim ${ }^{1}$, Per Erik Vullum ${ }^{2}$, Ann Mari Svensson ${ }^{1}$ and Fride

Vullum-Bruer ${ }^{1, *}$

${ }^{1}$ Department of Materials Science and Engineering, NTNU, Norwegian University of

Science and Technology, NO-7491 Trondheim, Norway

${ }^{2}$ SINTEF Materials and Chemistry, NO-7491 Trondheim, Norway

* Corresponding Authors. E-mail: fride.vullum-bruer@ntnu.no 


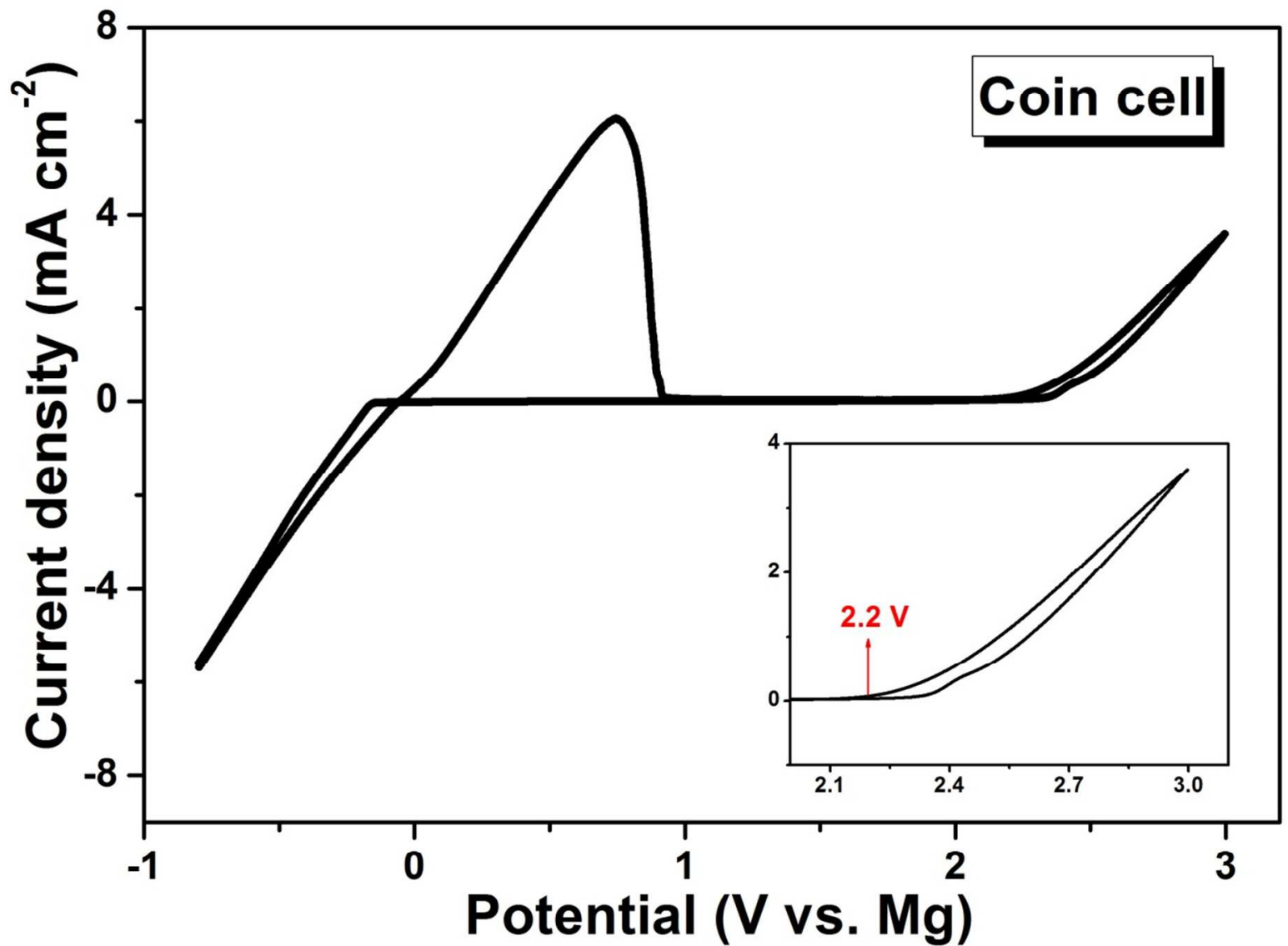

Figure S1. Typical cyclic voltammograms of $\mathrm{Mg}$ deposition-stripping in $0.4 \mathrm{M}$ APC electrolyte. Experiments are conducted on a coin cell, at a scan rate of $10 \mathrm{mV} \mathrm{s}^{-1}$ and room temperature with $\mathrm{Mg}$ metal as reference- and counter electrode. The inset shows the enlargement of the area between 2.1 and $3 \mathrm{~V}$. 


\section{Outside}

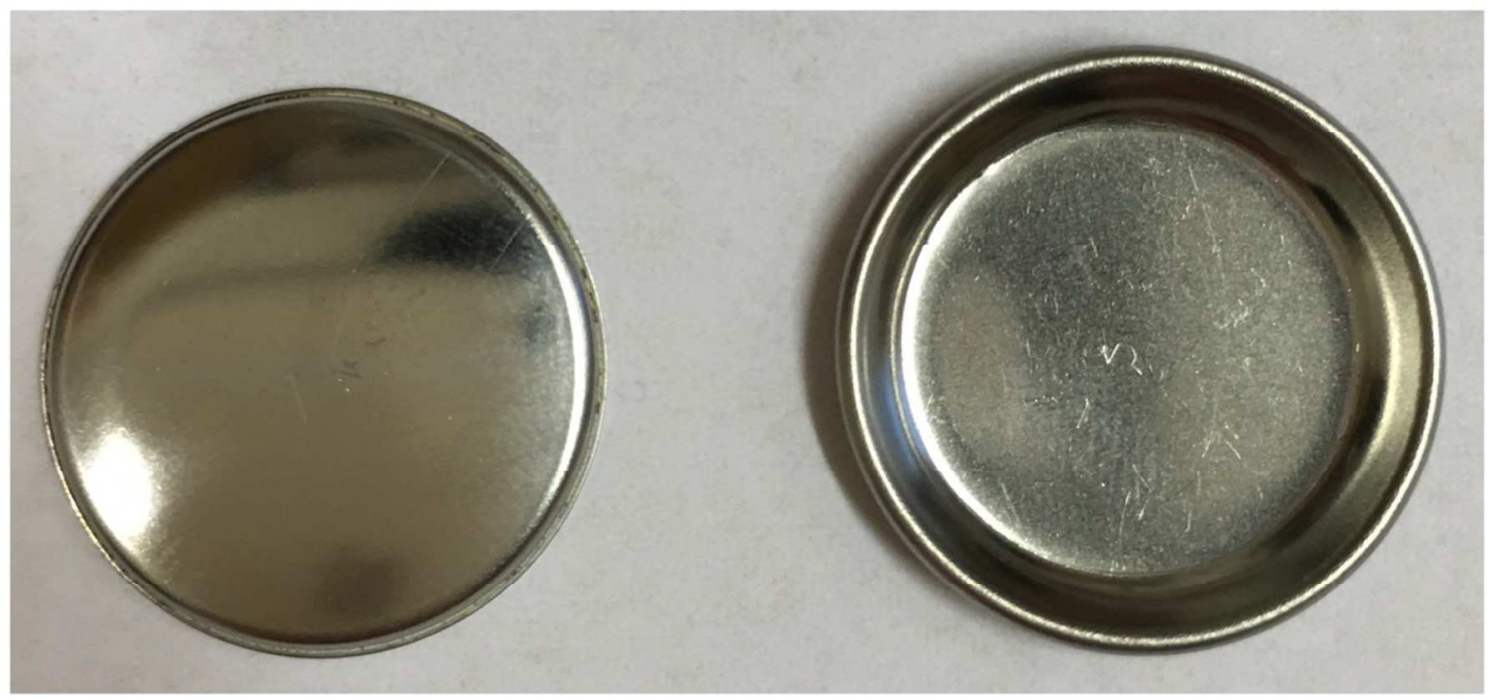

\section{Inside}

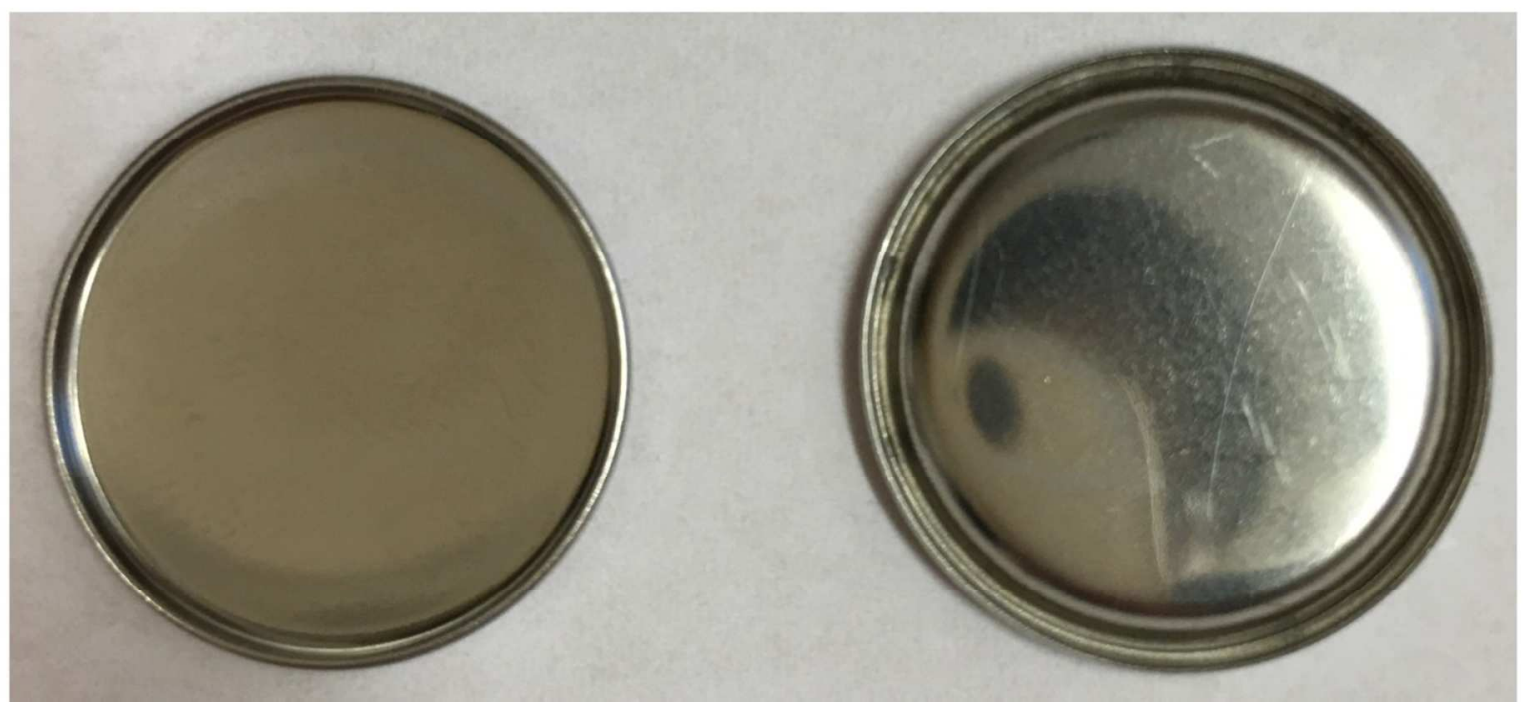

Figure S2. The photographs of a dissembled coin cell after 1000 cycles charge/discharge. The cell was washed by THF in order to clean the residual electrolyte and dried 2 hours at room temperature under vacuum. 


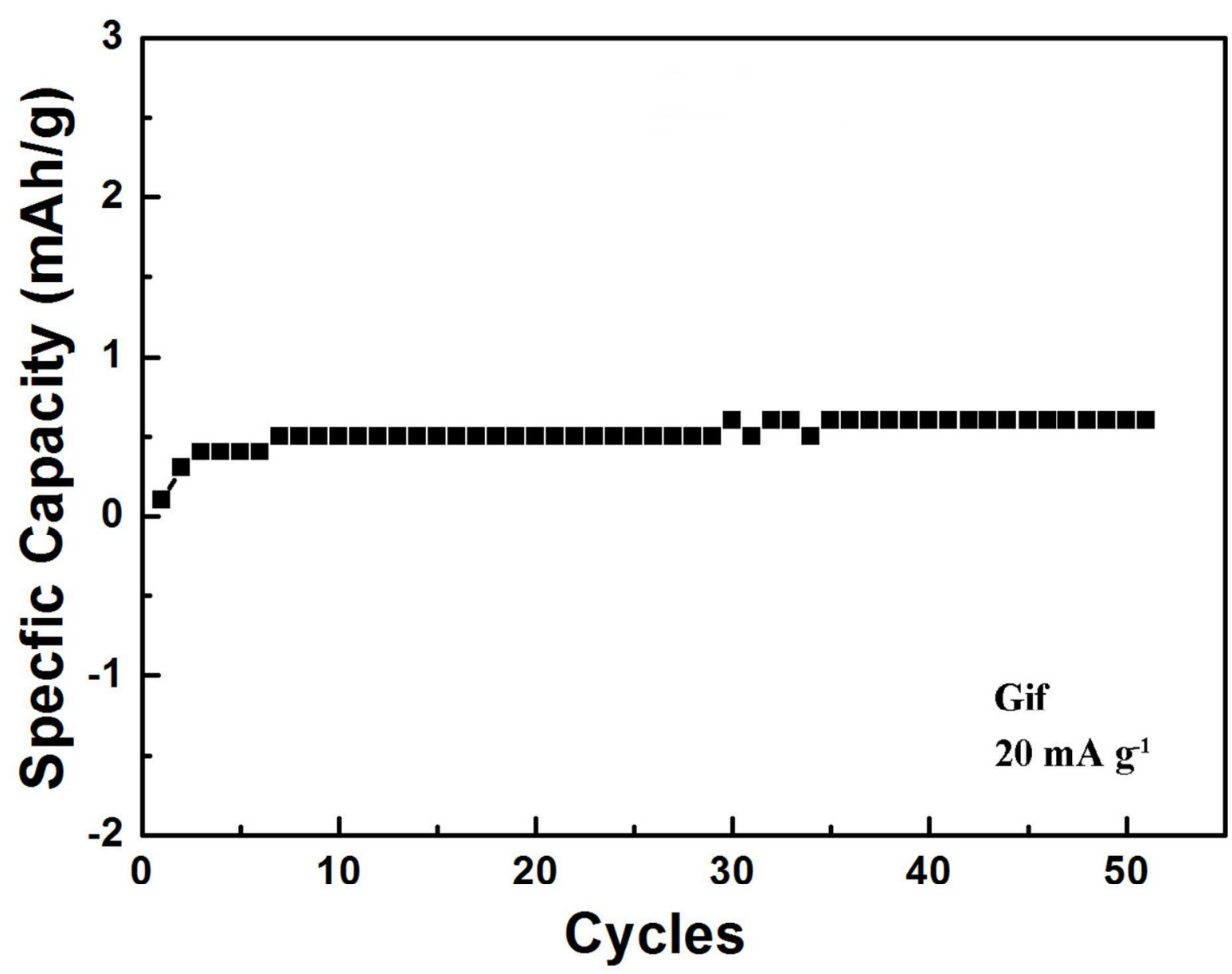

Figure S3. Cyclic stability of pure Gif cycled at $20 \mathrm{~mA} \mathrm{~g}^{-1}$. 


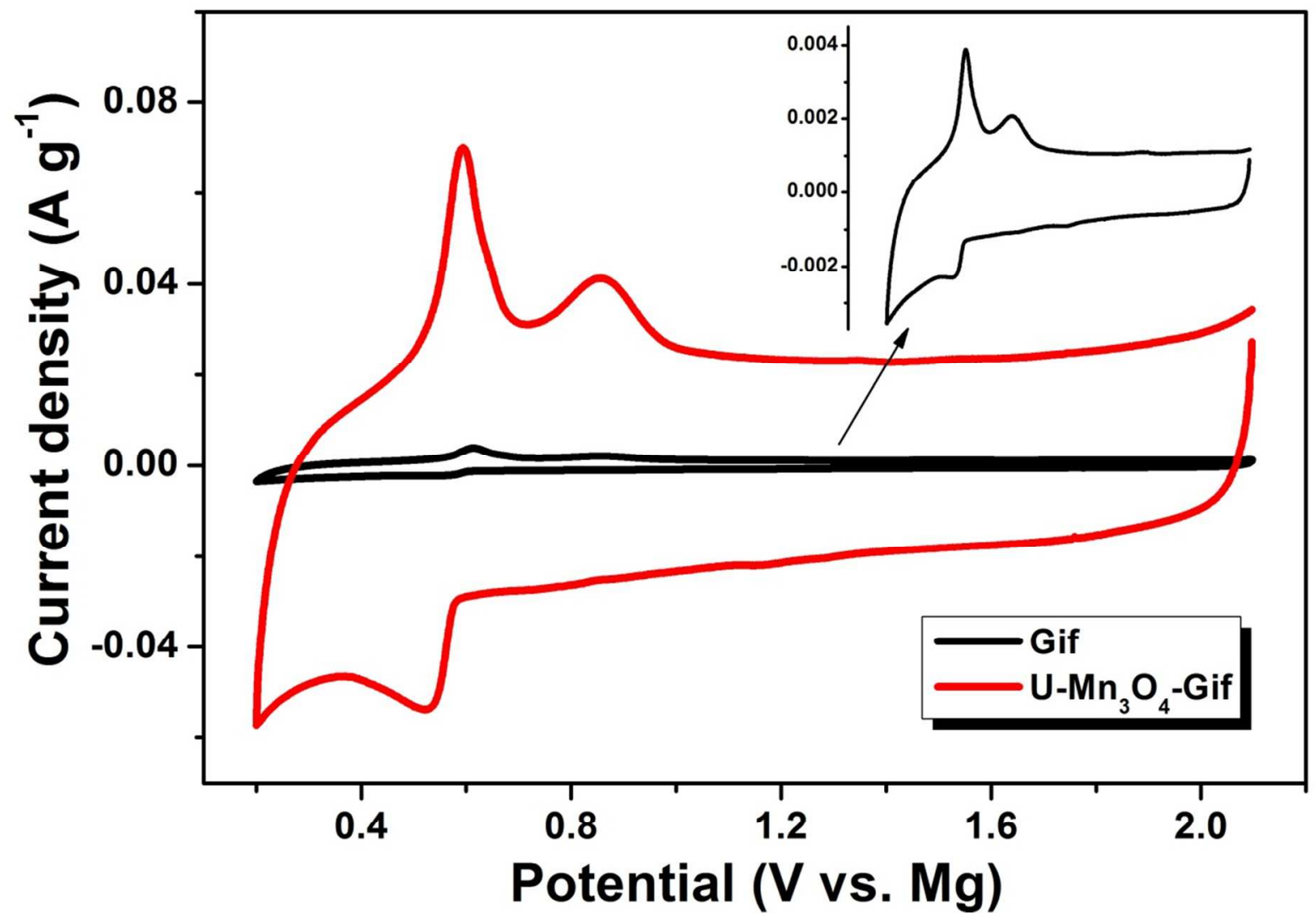

Figure S4. CV curve of $\mathrm{U}-\mathrm{Mn}_{3} \mathrm{O}_{4}$ at the scan rate of $0.2 \mathrm{mV} \mathrm{s}^{-1}$ compared with pure Gif. The inset shows the CV curve of Gif. 